American Journal of Applied Sciences 7 (8): 1093-1099, 2010

ISSN 1546-9239

(C) 2010 Science Publications

\title{
Experimental Investigation of Cluster Bed-Form Formation Over Uniform Sediment
}

\author{
Masoud Karbasi, Mohammad H. Omid and Javad Farhoudi \\ Department of Irrigation Engineering, University of Tehran, Iran
}

\begin{abstract}
Problem statement: Cluster microforms are a type of small scale bed-form found in the surface layer of some gravel bed rivers. These bed-forms are comprised of discrete, organized groupings of particles that sit above the average elevation of the surrounding bed. As part of the structural organization of the bed, clusters are believed to impact the local dynamics of the fluvial system through the feedback process involving the flow field, entrainable sediment and stable bed morphology. Approach: In this study, flow and sediment characteristic measured at a laboratory flume and the presence or absence of clusters at each of these tests was recorded. A statistical analysis using logistic regression was performed to examine the correlation between the occurrence of clusters and various non-dimension combinations of measured variables. Results: It was found that the best parameters for predicting the clusters presence are $\mathrm{gd}_{\mathrm{u}}^{2} / \mathrm{hU}^{2}{ }_{\text {avg }}$ and $\mathrm{gd}^{2}{ }_{\mathrm{u}} / \mathrm{U}^{2}{ }_{\text {avg. }}$. In two parameters analysis it was found that clustering was best predicted by $\mathrm{gd}^{2}{ }_{\mathrm{u}} / \mathrm{U}^{2}{ }_{\text {avg }}$ and $\tau_{\mathrm{b}} / \rho \mathrm{U}^{2}{ }_{\text {avg. }}$. Conclusion: It is thought that these parameters work best at predicting the presence of clusters because they are descriptive of hydraulic and sedimentary conditions of tested reach.
\end{abstract}

Key words: Gravel-bed rivers, bed-forms, clusters, cluster prediction

\section{INTRODUCTION}

Geologists and engineers have long recognized fundamental differences between mountain channels and their lowland counterparts. In contrast to selfformed flood-plain channels, the gradient and morphology of mountain channels are tremendously variable and prone to forcing by external influences. Montgomery and Buffington (1997) Although mountain channels provide important aquatic habitat (Frissell, 1993), supply sediment to estuaries and the oceans (Milliman and Syvitski, 1992) and transmit land use disturbances from headwater areas down through drainage networks, they have received relatively little study compared to lowland rivers.

Improved ability to relate morphology and processes in mountain channels would facilitate understanding and predicting their response to both human and natural disturbance.

An important characteristic of gravel-bed Rivers is their variable bed topography. Gravel bed Rivers contains two scale-classes of bed-forms: (1) macroscale or macro-forms, e.g., step-pool and pool-riffle sequences (Bowman, 1977) and (2) micro-scale or cluster microforms, e.g., cellular structures and pebble clusters (Brayshaw, 1984; Reid and Hassan, 1992; Church et al., 1998; Lawless and Roberts 2001;
Papanicolaou et al., 2003). This study concentrates on cluster microforms.

Probably the Brayshaw et al. (1983) study was the first study highlighted the need to improve our understanding of the mechanisms starting cluster formation and disintegration and to explore their influence on the streambed stability. Subsequently, different field and laboratory studies have been performed and have led to the existence of two theories on this topic.

The first theory supports the idea that clusters provide additional bed stability. Field and laboratory observations of Hassan and Reid (1990); Reid and Hassan (1992); Church et al. (1998) and Kozlowski and Ergenzinger (1999), among others, suggest that clusters resist to high flow (i.e., they provide higher form resistance) and delay sediment entrainment in rivers by entrapping sediment particles along their perimeter and within the core of their structure. The laboratory experiments of Schuyler and Papanicolaou (2000) indicate similar results with the above studies.

The second theory is that clusters do not provide any additional bed stability. According to Carling and Orr (2000), clusters appear to break up at even lower bed shear stresses than those required initiating sediment motion of a single particle. Similarly, Billi (1988) concluded, from field observations in Farma

Corresponding Author: Masoud Karbasi, Department of Irrigation Engineering, University of Tehran, Iran 
River, Italy, that clusters do not delay sediment entrainment in gravel-bed streams.

It is believed that the presence of such varied bed topography depends largely upon the interlocking of individual particles of different size and specific gravity, the near-bed flow characteristics, sediment availability, longitudinal slope and the prevailing sediment transport conditions (Brayshaw et al., 1983; Hassan and Reid, 1990; Church et al., 1998). An improved understanding of the evolutionary processes of such bed forms is, therefore, important in gravel-bed Rivers for prediction of sediment transport and in-stream habitat evaluation.

For a cluster to form, two or more particles must group together. A cluster microform typically consists of an obstacle (the 'core' or 'anchor' sediment particle, which in most cases has a diameter greater than $D_{84}$, against which a 'stoss'-side accumulation of imbricated particles develops and behind which a 'wake tail' grows.

Storm et al. (2005) identified and classified individual clusters as being one of the five following shapes: pebble, heap, comet, line, or ring shaped clusters. Categories for these five types of cluster are determined visually based on the shape and sediment composition of each cluster and are used to help describe the heterogeneity of observed cluster shapes in natural field settings. Strom et al. (2004) used artificial glass particles as sediment and determine the conditions that cluster form.

In the previous researches, natural sediments have not been used to observe cluster formation. The main goal of this study is recognizing the conditions of flow and sediment in which cluster forms over uniform sized natural sediments.

\section{MATERIALS AND METHODS}

Experimental set up: One difficulty in the study of cluster microforms in natural streams is the fact that bed evolution occurs during high flow events, making it difficult to perform real-time flow measurements and bed micro topography observations during the formation and break up process of clusters. A laboratory flume study was conducted here so that sediment and flow conditions were precisely controlled and recorded at all times.

\begin{tabular}{ll}
\multicolumn{2}{l}{ Table 1: Summary of experimental conditions } \\
\hline Discharge & $6-87 \mathrm{~L} \mathrm{sec}^{-1}$ \\
\hline Slope & 0.01 and 0.005 \\
Depth & $0.017-0.11 \mathrm{~m}$ \\
Average velocity & $0.37-1.16 \mathrm{~m} \mathrm{sec}^{-1}$ \\
Sediment size & $8.73,11.1,15.9$ and $20.1 \mathrm{~mm}$ \\
Froude number & $0.52-1.29$ \\
\hline
\end{tabular}

Experiments were performed in a channel of Perspex sides and a smooth bed made of Perspex and of rectangular cross-section $0.9 \mathrm{~m}$ width and $18 \mathrm{~m}$ length. The downstream end of the channel was provided by a sediment trap with a collecting basket.

In order to meet the goals of this study, experiments performed in different conditions of discharge, channel slope and sediment size. In these tests, sediment particles were distributed over the bed and then the flow was established over the bed. After $30 \mathrm{~min}$ or reaching equilibrium conditions where we did not observe movement over the bed, experiment has been stopped and cluster formation has been assessed. Table 1 shows summary of experimental conditions and sediment sizes that have been used in this study.

Totally 47 experiments have been performed in our study.

Dimensional analysis: In engineering the application of fluid mechanics in designs make much of the use of empirical results from a lot of experiments. This data is often difficult to present in a readable form. Even from graphs it may be difficult to interpret. Dimensional analysis provides a strategy for choosing relevant data and how it should be presented. This is a useful technique in all experimentally based areas of engineering. If it is possible to identify the factors involved in a physical situation, dimensional analysis can form a relationship between them. The resulting expressions may not at first sight appear rigorous but these qualitative results converted to quantitative forms can be used to obtain any unknown factors from experimental analysis.

In this step we should determine effective variables on cluster formation:

$$
\mathrm{C}=\mathrm{f}\left(\mathrm{U}_{\text {avg }}, \tau_{\mathrm{b}}, \mu, \mathrm{S}, \mathrm{h}, \mathrm{g}, \rho, \rho_{\mathrm{s}}, \mathrm{d}_{\mathrm{u}}\right)
$$

Where:

g = The acceleration of gravity

$\mathrm{U}_{\mathrm{avg}} \quad=$ Mean stream wise velocity

$\tau_{\mathrm{b}}=$ Mean bed shear stress over the experimental reach

$\mu \quad=$ Dynamic viscosity of water

$\mathrm{d}_{\mathrm{u}} \quad=$ Diameter of uniform sediment particles that were used for cluster formation

$\mathrm{S} \quad=$ Slope of the channel

h $\quad=$ Water depth

$\rho$ and $\rho_{\mathrm{s}}=$ Fluid and sediment densities

By dimensional analysis using Buckingham theory one can find non-dimension groups of variables: 


$$
\mathrm{C}=\varphi\left(\frac{\tau_{\mathrm{b}}}{\rho \mathrm{U}_{\text {avg }}^{2}}, \frac{\mu}{\rho \mathrm{U}_{\text {avg }} \mathrm{d}_{\mathrm{u}}}, \frac{\mathrm{h}}{\mathrm{d}_{\mathrm{u}}}, \frac{\mathrm{gd}_{\mathrm{u}}}{\mathrm{U}_{\text {avg }}^{2}}, \frac{\rho_{\mathrm{s}}}{\rho}, \mathrm{S}\right)
$$

Some of above non-dimension numbers are constant and we can ignore them. Finally these four non-dimension numbers have been chosen for further analysis:

$$
\pi_{1}=\frac{\tau_{\mathrm{b}}}{\rho \mathrm{U}_{\text {avg }}^{2}}, \pi_{2}=\frac{\mu}{\rho \mathrm{U}_{\text {avg }} \mathrm{d}_{\mathrm{u}}}, \pi_{3}=\frac{\mathrm{h}}{\mathrm{d}_{\mathrm{u}}}, \pi_{4}=\frac{\mathrm{gd}_{\mathrm{u}}}{\mathrm{U}_{\text {avg }}^{2}}
$$

Multiplying and dividing combinations of nondimension numbers yields dimensionless variables that combine several possible descriptive variables from Eq. 1 into single predictive parameters.

Statistical analysis: The statistical analysis was performed by using SPSS software.

Logistic regression: In statistics, logistic regression (sometimes called the logistic model or logit model) is used for prediction of the probability of occurrence of an event by fitting data to a logistic curve. It is a generalized linear model used for binomial regression. Like many forms of regression analysis, it makes use of several predictor variables that may be either numerical or categorical.

Logistic regression relates the probability of success, $\pi$ to the predictor variables in the form of:

$$
\pi(\mathrm{x})=\frac{\mathrm{e}^{\mathrm{Y}}}{1+\mathrm{e}^{\mathrm{Y}}}
$$

Where:

$$
\mathrm{Y}=\alpha+\sum_{\mathrm{i}=1}^{\mathrm{k}} \beta_{\mathrm{i}} \mathrm{x}_{\mathrm{i}}
$$

is the predictor statistic, the $x_{\mathrm{i}}$ represents the predictor variables with $\mathrm{i}=1,2,3, \ldots, \mathrm{k}$ The fitted model coefficients $\alpha$ and $\beta_{\mathrm{j}}$ are solved for by maximizing the likelihood function:

$$
\ell(\beta)=\prod_{j=1}^{n}\left[\pi\left(x_{j}\right)\right]^{y_{j}}\left[1-\pi\left(x_{j}\right)\right]^{\left(1-y_{j}\right)}
$$

The maximum likelihood corresponds to the values of $\beta_{i}$ that maximize the probability of obtaining the observed data. The value of $\pi(\mathrm{x})$ ranges from $0-1$ and represents the probability that the desired outcome will occur.
Logistic regression models predicting $\mathrm{C}$ as a function of the predictor variables were then systematically fitted in a stepwise manner starting with all bivariate models. The statistical significance of each predictor variable was assessed using the difference in the residual deviance between the bivariate models and the null model, where the residual deviance is defined as:

$$
\mathrm{D}_{\mathrm{R}}=-2 \ln (\ell(\mathrm{B}))
$$

The goal of the statistical model is to determine which variable, or combination of variables, are the most statistically significant for predicting the occurrence of clusters. To do this, the statistical significance of each parameter and the overall ability of the regression model to accurately predict the occurrence of clusters were assessed.

Model selection and assessment of predictive ability: Model selection was based on the assessment of a combination of four statistical measures:

- Akaike Information Criterion (AIC): The AIC is defined as $\mathrm{AIC}=\mathrm{D}_{\mathrm{R}}+2(\mathrm{n}+1)$ where $\mathrm{n}$ is the number of predictor variables used; it is a statistical measure that penalizes for the inclusion of extra predictor variables and can be used to compare models with different numbers of predictor variables

- The ROC curves: The ROC curves are plots of the model's predicted True Positive Fraction (TPF) (model sensitivity) versus the model's predicted False Positive Fraction (FPF) (1-specificity) over the full range of possible so-called 'cut-values', i.e., the value of $\pi(x)$ chosen to describe between predicted outcomes of $\mathrm{C}=0$ and $\mathrm{C}=1$. A model that performs well will show a rapid increase in the TPF with a relatively small increase in the FPF. Because of the relationship between the ROC curve and the model's predictive power, a simple integration of the ROC curve produces a singlevalue statistic that is indicative of the overall predictive accuracy of the model. This statistic is known as the 'area under the curve,' or the AUC. Classification of a model's predictive ability using AUC values can be based on the following scale: $0 \cdot 5-0 \cdot 6=$ fail; $0 \cdot 6-0 \cdot 7=$ poor; $0 \cdot 7-0 \cdot 8=$ fair; $0 \cdot 8-0 \cdot 9=$ good $; 0 \cdot 9-1 \cdot 0=$ excellent $($ Miska and Jan, 2005)

- Cox and Snell $\mathrm{R}^{2}$ and Nagelkerke $\mathrm{R}^{2}$ : The Cox and Snell $R^{2}$ can be interpreted like $R^{2}$ in a multiple regression, but cannot reach a maximum value of 1. The Nagelkerke $R^{2}$ can reach a maximum of 1 
- The true classification measure shows us that this rule allows us to correctly classify of the subjects where the predicted event was observed. For example true classification value of $90 \%$ shows us that this predictive variable can classify the clustered or non-clustered condition by accuracy of $90 \%$. Higher values of this measure show the accuracy of the model

\section{RESULTS}

One predictive variable: The predictor variables that performed best in describing $\mathrm{C}$ are listed in Table 1 . The Wald statistic in the Table 1 and the corresponding significance level test the significance of each of the covariate and dummy independents in the model. The ratio of the logistic coefficient $B$ to its standard error SE, squared, equals the Wald statistic. If the Wald statistic is significant (i.e., less than 0.05) then the parameter is significant in the model. The "Exp(b)" column is SPSS's label for the odds ratio of the row independent with the dependent (minority) (Table 2). It is the predicted change in odds for a unit increase in the corresponding independent variable. Odds ratios less than 1 correspond to decreases and odds ratios more than 1.0 correspond to increases in odds. Odds ratios close to 1.0 indicate that unit changes in that independent variable do not affect the dependent variable.
The single best discriminator between clustered and nonclustered sites is $\mathrm{gd}_{\mathrm{u}}^{2} / \mathrm{U}_{\text {avg }}^{2} \mathrm{~h}$. The values of model are AIC $=28.494$, AUC $=0.969$ Nagelkerke $\mathrm{R}^{2}=0.771$ and true classification $=91.5 \%$. The second good predictive variable is $\mathrm{gd}_{\mathrm{u}} / \mathrm{U}_{\text {avg }}^{2}$. The values: $\mathrm{AIC}=$ 28.526, $\mathrm{AUC}=0.955$ Nagelkerke R Square $=0.770$ and true classification $=85.1 \%$.

An interesting note is that the inclusion of slope in the predictive models had the effect of making the predictions worse.

The predictive relations for the occurrence of clusters using $\mathrm{gd}_{\mathrm{u}}^{2} / \mathrm{U}_{\text {avg }}^{2} \mathrm{~h}$ and $\mathrm{gd}_{\mathrm{u}} / \mathrm{U}_{\text {avg }}^{2}$ are:

$$
\begin{aligned}
& \pi\left(\mathrm{gd}_{\mathrm{u}}^{2} / \mathrm{U}_{\text {avg }}^{2} \mathrm{~h}\right)=\frac{\mathrm{e}^{4.42-0.254\left(\mathrm{gd}_{\mathrm{u}}^{2} / \mathrm{U}_{\text {avg }}^{2} \mathrm{~h}\right)}}{1+\mathrm{e}^{4.42-0.254\left(\mathrm{gd}_{\mathrm{u}} / \mathrm{U}_{\text {avg }}^{2} \mathrm{~h}\right)}} \\
& \pi\left(\mathrm{gd}_{\mathrm{u}} / \mathrm{U}_{\text {avg }}^{2}\right)=\frac{\mathrm{e}^{-6.118+23.183\left(\mathrm{gd}_{\mathrm{u}} / \mathrm{U}_{\text {avg }}^{2}\right)}}{1+\mathrm{e}^{-6.118+23.183\left(\mathrm{gd}_{\mathrm{u}} / \mathrm{U}_{\text {avg }}^{2}\right)}}
\end{aligned}
$$

Using the AUC classification scale, these two models are classified as excellent in predictive accuracy. Figure 1 shows plots of logistic regression results and corresponding ROC curves for our best predictive variables.

\begin{tabular}{|c|c|c|c|c|c|c|c|c|c|c|c|}
\hline Predictor & $\begin{array}{l}\text { Model } \\
\text { variables }\end{array}$ & $\mathrm{B}$ & SE & Wald & Sig. & $\begin{array}{l}\text { Cox and } \\
\text { Snell } \mathrm{R}^{2}\end{array}$ & $\begin{array}{l}\text { Nagelkerke } \\
\mathrm{R}^{2}\end{array}$ & $\operatorname{Exp}(B)$ & $\begin{array}{l}\text { True } \\
\text { classification }\end{array}$ & AIC & AUC \\
\hline \multirow[t]{2}{*}{$\tau_{\mathrm{b}} / \rho \mathrm{U}_{\text {avg }}^{2}$} & Variable & 988.562 & 298.542 & 10.965 & 0.001 & 0.393 & 0.524 & 0.000 & 85.1 & 45.532 & 0.898 \\
\hline & Constant & -6.954 & 2.079 & 11.161 & 0.001 & & & 0.001 & & & \\
\hline \multirow[t]{2}{*}{$\mu / \rho U_{\text {avg }} d_{u}$} & Variable & 14073.870 & 06637.472 & 4.496 & 0.034 & 0.117 & 0.156 & 0.000 & 59.6 & 63.116 & 0.691 \\
\hline & Constant & -1.515 & 0.804 & 3.550 & 0.060 & & & 0.219 & & & \\
\hline \multirow[t]{2}{*}{$\mathrm{h} / \mathrm{d}_{\mathrm{u}}$} & Variable & -1.125 & 0.331 & 11.571 & 0.001 & 0.391 & 0.522 & 0.324 & 78.7 & 45.682 & 0.885 \\
\hline & Constant & 4.768 & 1.394 & 11.699 & 0.001 & & & 117.662 & & & \\
\hline \multirow[t]{2}{*}{$\mathrm{gd}_{\mathrm{u}} / \mathrm{U}_{\mathrm{avg}}^{2}$} & Variable & 23.183 & 7.689 & 9.091 & 0.003 & 0.577 & 0.770 & $1.17 \mathrm{E}+10$ & 85.1 & 28.526 & 0.955 \\
\hline & Constant & -6.118 & 1.934 & 10.003 & 0.002 & & & 0.002 & & & \\
\hline \multirow[t]{2}{*}{$\tau_{\mathrm{b}} / \rho S U_{\mathrm{avg}}$} & Variable & 1.722 & 0.666 & 6.681 & 0.010 & 0.193 & 0.258 & 5.599 & 61.7 & 58.878 & 0.795 \\
\hline & Constant & -1.606 & 0.702 & 5.597 & 0.018 & & & 0.190 & & & \\
\hline \multirow[t]{2}{*}{$\mu / \rho S U^{2}{ }_{\text {avg }} d_{u}$} & Variable & 75.850 & 37.473 & 4.097 & 0.043 & 0.111 & 0.149 & $8.74 \mathrm{E}+32$ & 66.0 & 63.408 & 0.716 \\
\hline & Constant & -1.119 & 0.659 & 2.887 & 0.089 & & & 0.326 & & & \\
\hline \multirow[t]{2}{*}{$\mathrm{h} / \mathrm{Sd}_{\mathrm{u}}$} & Variable & -0.002 & 0.001 & 3.961 & 0.047 & 0.101 & 0.135 & 0.998 & 57.4 & 63.953 & 0.685 \\
\hline & Constant & 1.128 & 0.570 & 3.914 & 0.048 & & & 3.089 & & & \\
\hline \multirow[t]{2}{*}{$\mathrm{gd}_{\mathrm{u}} / \mathrm{SU}_{\mathrm{avg}}^{2}$} & Variable & 0.060 & 0.020 & 8.849 & 0.003 & 0.392 & 0.523 & 1.061 & 70.2 & 45.576 & 0.896 \\
\hline & Constant & -2.318 & 0.770 & 9.058 & 0.003 & & & 0.098 & & & \\
\hline \multirow[t]{2}{*}{$\mathrm{gd}_{\mathrm{u}}^{2} / \mathrm{U}_{\text {avg }}^{2} \mathrm{~h}$} & Variable & -0.254 & 0.076 & 11.069 & 0.000 & 0.577 & .771 & 0.775 & 91.5 & 28.494 & 0.969 \\
\hline & Constant & 4.428 & 1.305 & 11.500 & 0.001 & & & 83.839 & & & \\
\hline \multirow[t]{2}{*}{$\tau_{\mathrm{b}} \mathrm{d}_{\mathrm{u}} / \mathrm{U}_{\mathrm{avg}} \mu$} & Variable & 0.009 & 0.010 & 0.727 & 0.394 & 0.016 & 0.021 & 1.009 & 48.9 & 68.226 & 0.555 \\
\hline & Constant & -0.504 & 0.795 & 0.402 & 0.526 & & & 0.604 & & & \\
\hline \multirow[t]{2}{*}{$\tau_{\mathrm{b}} \mathrm{h} / \rho \mathrm{U}_{\text {avg }}^{2} \mathrm{~d}_{\mathrm{u}}$} & Variable & -26.263 & 22.165 & 1.404 & 0.236 & 0.039 & 0.052 & 0.000 & 55.3 & 67.090 & 0.618 \\
\hline & Constant & 0.930 & 0.725 & 1.648 & 0.199 & & & 2.535 & & & \\
\hline \multirow[t]{2}{*}{$\tau_{\mathrm{b}} \mathrm{d}_{\mathrm{u}} \mathrm{g} / \rho \mathrm{U}_{\mathrm{avg}}^{4}$} & Variable & 1942.235 & 628.657 & 9.549 & 0.002 & 0.548 & 0.732 & 0.000 & 87.2 & 31.362 & 0.953 \\
\hline & Constant & -3.814 & 1.131 & 11.361 & 0.001 & & & 0.022 & & & \\
\hline \multirow[t]{2}{*}{$\mu \mathrm{h} / \rho \mathrm{U}_{\mathrm{avg}} \mathrm{d}_{\mathrm{u}}^{2}$} & Variable & -1290.700 & 900.255 & 2.056 & 0.152 & 0.050 & 0.067 & 0.000 & 61.7 & 66.536 & 0.635 \\
\hline & Constant & 0.786 & 0.537 & 2.143 & 0.143 & & & 2.194 & & & \\
\hline \multirow[t]{2}{*}{$\mu \mathrm{g} / \rho \mathrm{U}_{\mathrm{avg}}^{3}$} & Variable & 118038.944 & 35054.153 & 11.339 & 0.001 & 0.540 & 0.721 & 0.000 & 91.5 & 32.457 & 0.945 \\
\hline & Constant & -3.670 & 1.046 & 12.301 & 0.000 & & & 0.025 & & & \\
\hline
\end{tabular}

Table 2: Results from the statistical analysis for one predictive relationship 
Am. J. Applied Sci., 7 (8): 1093-1099, 2010

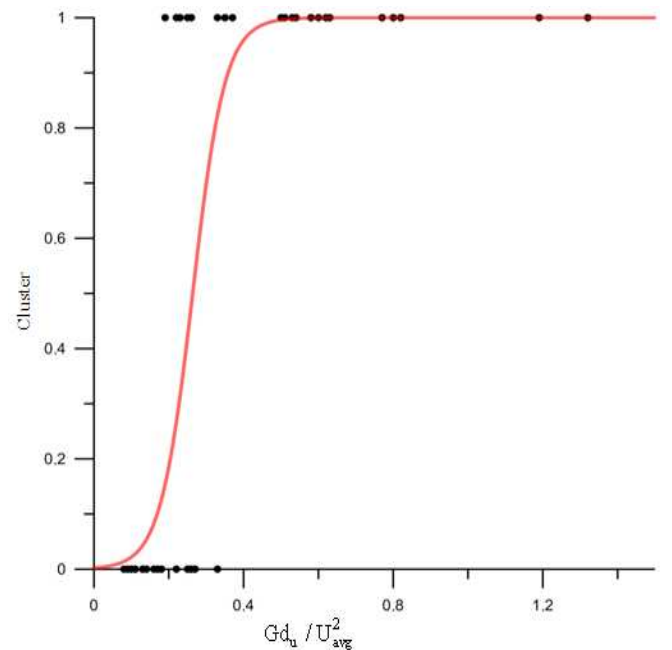

(a)

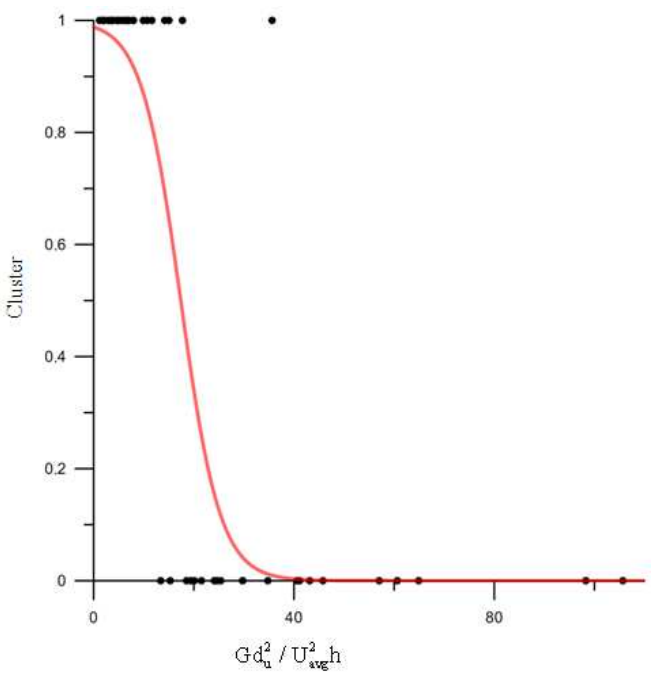

(c)

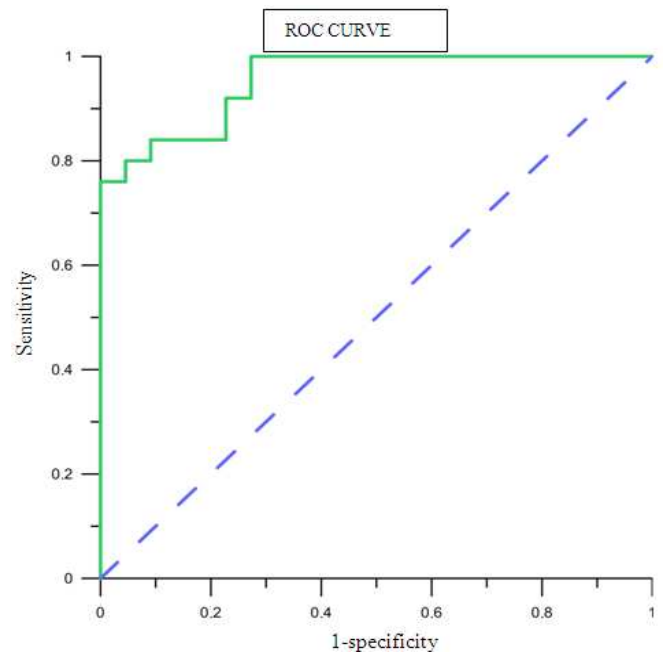

(b)

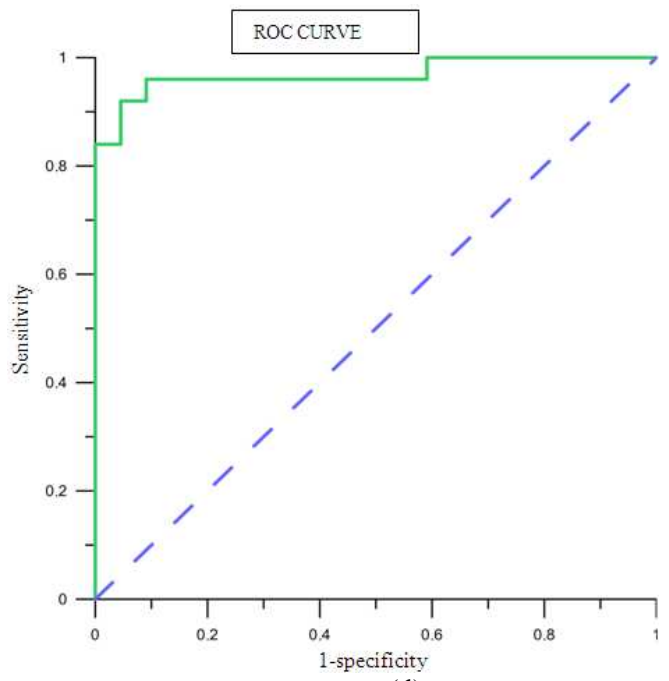

(d)

Fig. 1: Plots of logistic regression results and corresponding ROC curves

Table 3: Results from the statistical analysis for two predictive relationship

\begin{tabular}{|c|c|c|c|c|c|c|c|c|c|c|c|}
\hline Predictor & $\begin{array}{l}\text { Model } \\
\text { variables }\end{array}$ & B & SE & Wald & Sig. & $\begin{array}{l}\text { Cox and } \\
\text { Snell } R^{2}\end{array}$ & $\begin{array}{l}\text { Nagelkerke } \\
\mathrm{R}^{2}\end{array}$ & $\operatorname{Exp}(B)$ & $\begin{array}{l}\text { True } \\
\text { classification }\end{array}$ & AIC & AUC \\
\hline \multirow[t]{3}{*}{$\pi_{1}, \pi_{2}$} & VAR00001 & 925.945 & 322.604 & 8.238 & 0.004 & 0.395 & 0.527 & 0.000 & 83.0 & 47.360 & 0.900 \\
\hline & VAR00002 & 3321.683 & 8083.056 & 0.169 & 0.681 & & & 0.000 & & & \\
\hline & Constant & -6.902 & 2.407 & 11.369 & 0.001 & & & 0.001 & & & \\
\hline \multirow[t]{3}{*}{$\pi_{1}, \pi_{3}$} & VAR00001 & 1361.794 & 478.304 & 8.106 & 0.004 & 0.592 & 0.790 & 0.000 & 97.9 & 28.856 & 0.965 \\
\hline & VAR00003 & -1.221 & 0.407 & 8.985 & 0.003 & & & 0.295 & & & \\
\hline & Constant & -4.537 & 2.629 & 2.977 & 0.084 & & & 0.011 & & & \\
\hline \multirow[t]{3}{*}{$\pi_{1}, \pi_{4}$} & VAR00001 & -102.654 & 357.738 & 0.082 & 0.774 & 0.587 & 0.771 & 0.000 & 85.1 & 30.442 & 0.956 \\
\hline & VAR00004 & 24.376 & 8.819 & 7.640 & 0.006 & & & $3.85 \mathrm{E}+10$ & & & \\
\hline & Constant & -5.704 & 2.407 & 5.615 & 0.018 & & & 0.003 & & & \\
\hline \multirow[t]{3}{*}{$\pi_{2}, \pi_{3}$} & VAR00002 & 36839.711 & 14275.274 & 6.660 & 0.010 & 0.523 & 0.699 & 0.000 & 85.1 & 36.156 & 0.935 \\
\hline & VAR00003 & -1.594 & 0.508 & 9.864 & 0.002 & & & 0.203 & & & \\
\hline & Constant & 2.870 & 1.737 & 2.728 & 0.099 & & & 17.634 & & & \\
\hline \multirow{3}{*}{$\pi_{2}, \pi_{4}$} & VAR00002 & 13256.050 & 10458.786 & 1.606 & 0.205 & 0.593 & 0.792 & 0 & 89.4 & 28.709 & 0.964 \\
\hline & VAR00004 & 22.367 & 7.812 & 8.199 & 0.004 & & & $5.18 \mathrm{E}+09$ & & & \\
\hline & Constant & -7.438 & 2.372 & 9.838 & 0.002 & & & 0.001 & & & \\
\hline \multirow[t]{3}{*}{$\pi_{3}, \pi_{4}$} & VAR00004 & 22.773 & 9.275 & 6.028 & 0.014 & 0.610 & 0.815 & $7.76 \mathrm{E}+09$ & 89.4 & 26.679 & 0.964 \\
\hline & VAR00003 & -0.685 & 0.446 & 2.351 & 0.125 & & & 0.504 & & & \\
\hline & Constant & -3.009 & 2.742 & 1.204 & 0.272 & & & 0.049 & & & \\
\hline
\end{tabular}


Two predictive variables: The two predictor variables that performed best in describing $\mathrm{C}$ are listed in Table 3. The best combinations of parameters that describe the clustering are $\pi_{1}, \pi_{3}$. The values of model are $\mathrm{AIC}=28.857$, AUC $=0.965$ Nagelkerke $\mathrm{R}^{2}=0.790$ and true classification $=97.9 \%$. The predictive relation for the occurrence of clusters using $\pi_{1}, \pi_{3}$ is:

$\pi\left(\pi_{1}, \pi_{3}\right)=\frac{\mathrm{e}^{\left(-4.537+1361.794 \pi_{1}-0.221 \pi_{3}\right)}}{1+\mathrm{e}^{\left(-4.537+1361.794 \pi_{1}-0.221 \pi_{3}\right)}}$

\section{DISCUSSION}

The analyses were mentioned above have shown that, there is a statistical connection between the presence or absence of cluster microtopography and particular values of $\mathrm{gd}_{\mathrm{u}}^{2} / \mathrm{U}_{\text {avg }}^{2} \mathrm{~h}$ and $\mathrm{gd}_{\mathrm{u}} / \mathrm{U}_{\text {avg }}^{2}$. There are two key variable at this two parameter, $d_{u}$ and $U_{a v g}$. These two variables present sedimentary and hydraulic characteristics of tested reach. Due to constant channel geometry (except slope), there is no geometry variable in our non-dimension parameters. It has been shown in the results section that slope can not statistically describe the cluster formation. It is believed that, there is a statistical connection between channel geometry and clustering phenomena. It needs additional study on other laboratory flumes with different widths.

\section{CONCLUSION}

This study has focused on the identification of a parameter for the presence or absence of clusters in mountain streams. A laboratory study was conducted to record the presence and absence of clusters under different conditions of flow and sediment characteristics.

A dimensional analysis was performed to find meaningful dimensionless groups of variables that might be related to cluster formation and the statistical connection between the observance of clusters and the flow and sediment characteristics predictor variables was checked using logistic regression. follows:

The results of this study are summarized as

- Cluster microforms can form over uniform sized sediment particles. This confirms Storm et al. (2005) and Papanicolaou (2004) findings

- Clusters started to form once sediments began to move

- Individual variables that were found to be most descriptive in predicting clustered topography were $\mathrm{gd}_{\mathrm{u}}^{2} / \mathrm{U}_{\text {avg }}^{2} \mathrm{~h}$ and $\mathrm{gd}_{\mathrm{u}} / \mathrm{U}_{\text {avg }}^{2}$
- The development of a logistic regression model for the prediction using $\mathrm{gd}_{\mathrm{u}}^{2} / \mathrm{U}_{\text {avg }}^{2} \mathrm{~h}$ and $\mathrm{gd}_{\mathrm{u}} / \mathrm{U}_{\mathrm{avg}}^{2}$ showed that these two predictive parameters perform excellent in discriminating between predicting clustered and non-clustered tests. These logistic regression models have AUC values that ranged from $0.969-0.955$

- $\mathrm{gd}_{\mathrm{u}}^{2} / \mathrm{U}_{\text {avg }}^{2} \mathrm{~h}$ and $\mathrm{gd}_{\mathrm{u}} / \mathrm{U}_{\text {avg }}^{2}$ are good predictive variables because they present sedimentary and hydraulic characteristics of tested reach

- Two parameter analyses showed that $\mathrm{gd}_{\mathrm{u}} / \mathrm{U}_{\mathrm{avg}}^{2}$ and $\tau_{\mathrm{b}} / \rho \mathrm{U}_{\text {avg }}$ parameters can predict the cluster formation

- Parameters in two predictive variables also represent sedimentary and hydraulic characteristics of tested reach

\section{REFERENCES}

Billi, P., 1988. A note on cluster bedform behavior in a gravel-bed river. Catena, 15: 473-481. DOI: 10.1016/0341-8162(88)90065-3

Bowman, D., 1977. Stepped-bed morphology in arid gravelly channels. Geol. Soc. Am. Bull., 88: 291-298. DOI: $10.1130 / 0016-$ 7606(1977) 88<291:SMIAGC> 2.0.CO;2

Brayshaw, A.C., L.E. Frostick and I. Reid, 1983. Hydrodynamics of particle clusters and sediment entrainment in coarse alluvial channels. Sedimentology, 30: 137-143. DOI: 10.1111/j.1365-3091.1983.tb00656.x

Brayshaw, A.C., 1984. Characteristics and Origin of Cluster Bedforms in Coarsegrained Alluvial Channels. In: Sedimentology of Gravels and Conglomerates, Koster, E.H. and R.J. Steel (Eds.). Canadian Society of Petroleum Geologist, Canada, pp: 77-86.

Carling, P.A. and H.G. Orr, 2000. Morphology of rifflepool sequences in the River Severn, England. Earth Surface Process. Landforms, 25: 369-384. DOI: 10.1002/(SICI)1096-9837(200004)25:4<369::AIDESP60>3.0.CO;2-M

Church, M., M.A. Hassan and J.F. Wolcott, 1998. Stabilizing self-organized structures in gravel-bed stream channels: Field and experimental observations. Water Resour. Res., 34: 3169-3179. DOI: 10.1029/98WR00484

Frissell, C.A., 1993. Topology of extinction and endangerment of native fishes in the Pacific Northwest and California (U.S.A). Conservat. Biol., 7: 342-354. DOI: 10.1046/j.15231739.1993.07020342.x 
Hassan, M.A. and I. Reid, 1990. The influence of microform bed roughness elements on flow and sediment transport in gravel bed rivers. Earth Surface Process. Landforms, 15: 739-750. DOI: 10.1002/esp.3290150807

Kozlowski, B. and P. Ergenzinger, 1999. Ring structures-a specific new cluster type in steep mountain torrents. Proceedings of the 27th IAHR Congress, Aug. 28-28, IAHR, Austria, Graz, pp: 1-9.

Lawless, M. and A. Robert, 2001. Three-dimensional flow structure around smallscale bedforms in a simulated gravel-bed environment. Earth Surface Process. Landforms, 26: 507-522. DOI: 10.1002/esp. 195

Miska, L. and H. Jan, 2005. Evaluation of current statistical approaches for predictive geomorphological mapping. Geomorphology, 67: 299-315. DOI: 10.1016/j.geomorph.2004.10.006

Milliman, J.D. and J.P.M. Syvitski, 1992. Geomorphic/tectonic control of sediment discharge to the ocean: The importance of small mountainous rivers. J. Geol., 100: 525-544. DOI: $10.1086 / 629606$

Montgomery, D.R. and J.M. Buffington, 1997. Channel-reach morphology in mountain drainage basins. Geol. Soc. Am. Bull., 109: 596-611. DOI: $10.1130 / 0016-$

7606(1997)109<0596:CRMIMD>2.3.CO;2
Papanicolaou, A.N., K. Strom, A. Schuyler and N. Talebbeydokhti, 2003. The role of sediment specific gravity and availability on cluster evolution. Earth Surface Process. Landforms, 28: 69-86. DOI: 10.1002/esp.427

Reid, I. and M.A. Hassan, 1992. The influence of microform bed roughness elements on flow and sediment transport in gravel bed rivers: A reply. Earth Surface Process. Landforms, 17: 535-538. DOI: 10.1002/esp.3290170512

Schuyler, A. and A.N. Papanicolaou, 2000. Image analysis technique to track the evolution of sediment clusters. J. Exp. Tech., 24: 31-36. http://www.iihr.uiowa.edu/ apapanic/ThanosPaper s/Papanicolaou,\%20Schuyler\%20(Exp-tech).pdf

Storm, K.B., A.N. Papanicolaou, B. Billing, L.L. Ely and R.R. Hendrick, 2005. Characterization of particle cluster bedforms in mountain streams. Proceeding of the ASCE/E WR I World Water and Environmental Resources Congress, (WWERC'05), ASCE, Anchorage, AK., pp: 339-339.

Strom, K., A.N. Papanicolaou, N. Evangelopoulos and M. Odeh, 2004. Microforms in gravel bed rivers: Formation, disintegration and effects on bedload transport. J. Hydr. Eng., 130: 554-567. DOI: 10.1061/(ASCE)0733-9429(2004)130:6(554) 